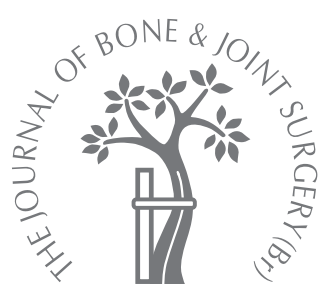

\title{
Pronator teres transfer to correct pronation deformity of the forearm after an obstetrical brachial plexus injury
}

\author{
A. Amrani, \\ M. A. Dendane, \\ Z. F. El Alami \\ From the Children's \\ Hospital of Rabat, \\ Rabat, Morocco
}

\begin{abstract}
A pronation deformity of the forearm following an obstetric brachial plexus injury causes functional and cosmetic disability. We evaluated the results of pronator teres transfer to correct their deformity in $\mathbf{1 4}$ children treated over a period of four years. The mean age at surgery was 7.6 years ( 5 to 15 ). The indication for surgery in each case was impairment of active supination in a forearm that could be passively supinated provided that there was no medial contracture of the shoulder and normal function of the hand. The median follow-up was $\mathbf{2 0 . 4}$ months (8 to 42). No patient was lost to follow-up. Qualitative results were also assessed. The median active supination improved from $5^{\circ}\left(0^{\circ}\right.$ to $\left.10^{\circ}\right)$ to $75^{\circ}\left(70^{\circ}\right.$ to $\left.80^{\circ}\right)$ with no loss of pronation.
\end{abstract}

A passively correctible pronation contracture can be corrected safely and effectively by the transfer of pronator teres.

One of the more common sequelae of an obstetric brachial plexus palsy is the loss of pronation or supination of the forearm. ${ }^{1}$ Pronation is more often restricted than is supination. ${ }^{1}$ A pronation contracture is caused by the unrestricted action of the pronator muscles of the forearm in the presence of weak or paralysed supinators. Although in its early stages a pronation contracture can be corrected passively, once the interosseous membrane contracts the deformity will become fixed. It has therefore been suggested that this should be corrected at an early stage. ${ }^{2}$ Because it is often associated with normal hand function, the aim of corrective surgery is to place the hand in its optimal functional position. Before considering surgery, it is essential to evaluate the condition of the interosseous membrane (elastic or contracted) and the radioulnar joint. The surgeon must also take into account any deformity of the shoulder and elbow, and these must be corrected before pronator teres transfer is contemplated. ${ }^{3}$

In this paper, we present our results of pronator teres transfer to correct the pronation deformity caused by obstetric brachial plexus injury.

\section{Patients and Methods}

Between 2004 and 2008, 14 pronator teres transfers were undertaken by the senior author (AA). There were eight boys and six girls, with a mean age of 7.6 years (5 to 15 ). The right shoulder was affected in nine patients and the left in five. There were 11 C5-6 palsies and three C5-7 palsies. The indication for operation in each case was impairment of active supination with full passive supination, and the arm in neutral position without a medial rotation contracture of the shoulder. The hand was normal in every case. The affected limbs were assessed clinically, both pre-operatively and post-operatively, for active and passive pronation and supination of the forearm (Table I). Particular care was taken to measure forearm rotation in isolation from shoulder movements. The patient was asked to hold a cylindrical object (e.g. a pen) in a neutral position before pronating and supinating the forearm. The angles between the vertical and the pen were taken to be the range of movement in each direction. The median follow-up was 20.4 months (8 to 42 ).

Surgical technique. A single incision was used, the pronator teres muscle was identified deep to the flexor carpi radialis, and its insertion identified and the tendon lengthened in $\mathrm{Z}$ fashion. The distal part was then re-routed dorsally to volarly through a window in the interosseous membrane and sutured to the proximal tendon under slight tension. This converted the pronator teres into a supinator muscle. After the operation, the forearm was placed in full supination in the cast for six weeks, and then rehabilitation was gradually introduced. 
Table I. Summary of patients

\begin{tabular}{|c|c|c|c|c|c|c|c|}
\hline Case & $\begin{array}{l}\text { Age } \\
\text { (yrs) }\end{array}$ & Gender & $\begin{array}{l}\text { Affected } \\
\text { side }\end{array}$ & $\begin{array}{l}\text { Surgery before } \\
\text { pronator teres transfer }\end{array}$ & $\begin{array}{l}\text { Pre-operative } \\
\text { supination }\left({ }^{\circ}\right)^{*}\end{array}$ & $\begin{array}{l}\text { Post-operative } \\
\text { supination }\left({ }^{\circ}\right)\end{array}$ & $\begin{array}{l}\text { Follow-up } \\
\text { (mths) }\end{array}$ \\
\hline 1 & 6.3 & M & $\mathrm{R}$ & Shoulder & 0 & 80 & 42 \\
\hline 2 & 5.8 & $M$ & $\mathrm{R}$ & Shoulder & 10 & 70 & 37 \\
\hline 3 & 5.1 & $\mathrm{~F}$ & $\mathrm{~L}$ & Shoulder & 10 & 80 & 35 \\
\hline 4 & 7.1 & $\mathrm{~F}$ & $\mathrm{R}$ & Shoulder & 0 & 80 & 27 \\
\hline 5 & 8.2 & M & $\mathrm{R}$ & Shoulder & 0 & 80 & 25 \\
\hline 6 & 6.8 & M & $\mathrm{R}$ & Shoulder & 10 & 80 & 22 \\
\hline 7 & 5.8 & $\mathrm{~F}$ & $\mathrm{~L}$ & Shoulder & 0 & 70 & 22 \\
\hline 8 & 12.5 & $\mathrm{~F}$ & $\mathrm{~L}$ & Humeral osteotomy & 0 & 80 & 20 \\
\hline 9 & 7.2 & M & $\mathrm{R}$ & Shoulder & 0 & 80 & 19 \\
\hline 10 & 15 & $F$ & $\mathrm{R}$ & Humeral osteotomy & 0 & 70 & 17 \\
\hline 11 & 5 & M & $\mathrm{R}$ & Shoulder & 10 & 80 & 13 \\
\hline 12 & 6.4 & M & $L$ & Shoulder & 0 & 80 & 12 \\
\hline 13 & 5.8 & $\mathrm{~F}$ & $\mathrm{R}$ & Shoulder & 10 & 80 & 9 \\
\hline 14 & 9.4 & $M$ & $\mathrm{~L}$ & No & 0 & 70 & 8 \\
\hline
\end{tabular}

* refers to active supination, all the patients have full passive supination

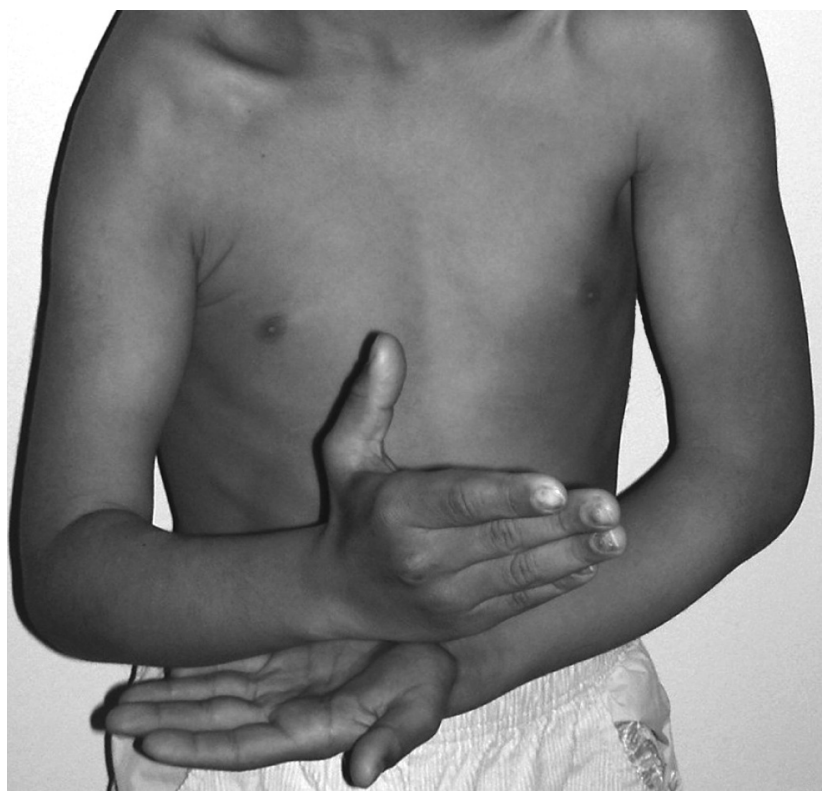

Fig. 1a

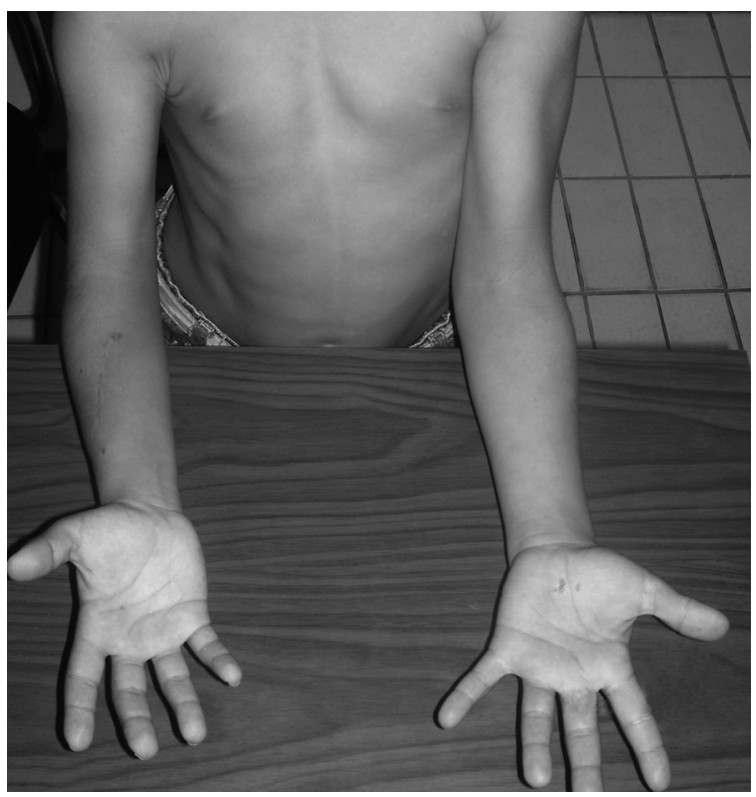

Fig. 1b

Photographs showing a six-year-old girl with a pronation deformity after obstetric brachial plexus injury a) pre-operatively, the supination was $0^{\circ}$ and b) six months after pronator teres transfer, with $70^{\circ}$ supination.

\section{Results}

The median active supination was $5^{\circ}\left(0^{\circ}\right.$ to $\left.10^{\circ}\right)$ preoperatively and $75^{\circ}\left(70^{\circ}\right.$ to $\left.80^{\circ}\right)$ at follow-up (Table I). All patients had a full range of pronation pre-operatively and at follow-up. They were able to dress themselves, eat and brush their teeth and hair more easily. Even when a child was able to perform a task pre-operatively, the increased dexterity after surgery allowed them to perform the same task with greater ease. Their parents also noticed a marked improvement in functional level and cosmetic appearance (Fig. 1). There were no complications.

\section{Discussion}

The typical posture of the upper limb in obstetric brachial plexus palsy is of adduction and internal rotation of the shoulder with pronation of the forearm. ${ }^{3,4}$ Deformities of forearm rotation are an almost universal finding and can be disabling. ${ }^{1}$ The use of the entire upper extremity is affected. An active supination $<10^{\circ}$ makes it difficult to bring the hand to the mouth in the absence of abduction and flexion of the shoulder. Operative intervention aims to correct the pronation deformity, thereby placing the hand in a more functional position. 
Savva, McAllen and Giddins ${ }^{5}$ noted that the strength of supination increases with external rotation of the shoulder. This suggests that any procedure that improves external rotation of the shoulder may influence rotation of the forearm. We only correct a pronation deformity of the forearm once the shoulder deformity has been addressed and the arm is in neutral. Supination is required for daily activities such as turning a key or a door knob, receiving change, personal hygiene, or just playing with other children., ${ }^{4,6}$ Therefore, procedures that aim to restore forearm function must correct the pronation deformity, produce active supination and avoid a secondary supination contracture. ${ }^{4,8}$ An uncorrected pronation contracture may, with growth, lead to fixed deformities of the radius and ulna that require radial osteotomy to place the forearm in a functional position. Posterior dislocation of the radial head may also occur. ${ }^{3}$

The treatment of the supination deformity that can follow a brachial plexus injury is well described in the literature $e^{1,2,4,9,10}$ and the benefit of treatment is well established. There is, however, little information about treating the pronation contracture. Yang et $\mathrm{al}^{8}$ reported four patients successfully treated by flexor carpi radialis transfer. Liggio et $\mathrm{al}^{4}$ reported the outcome of seven children with pronation contractures treated surgically by transfers of flexor carpi ulnaris, pronator teres and flexor carpi radialis with success.

The children in our series gained an average of $75^{\circ}$ of active supination after surgery. More important, however, were the gains in function and the improved appearance of the forearm. All the parents were very satisfied. This strongly supports the view that children with pronation contractures of the forearm secondary to obstetric brachial plexus injury can benefit from surgical reconstruction. ${ }^{4,9}$ Intensive post-operative physical therapy is essential to prevent recurrence of the contracture.

No benefits in any form have been received or will be received from a commer cial party related directly or indirectly to the subject of this article.

\section{References}

1. Sibinski M, Sherlock DA, Hems TE, Sharma H. Forearm rotational profile in obstetric brachial plexus injury. J Shoulder Elbow Surg 2007;16:784-7.

2. Zancolli EA. Paralytic: supination contracture of the forearm. J Bone Joint Surg [Am] 1967;49-A:1275-84

3. Aitken J. Deformity of the elbow joint as a sequel to Erb's obstetrical paralysis. $J$ Bone Joint Surg [Br] 1952;34-B:352-65.

4. Liggio FJ, Tham S, Price A, et al. Outcome of surgical treatment for forearm pronation deformities in children with obstetrical brachial plexus injuries. J Hand Surg $[\mathrm{Br}]$ 1999;24:43-5.

5. Savva N, McAllen CJ, Giddins GE. The relationship between the strength of supination of the forearm and rotation of the shoulder. J Bone Joint Surg $[\mathrm{Br}]$ 2003;85B:406-7.

6. Gschwind C, Tonkin M. Surgery for cerebral palsy. Part I: classification and operative procedures for pronation deformity. J Hand Surg [Br] 1992;17:391-5.

7. Bunata RE. Pronator teres rerouting in children with cerebral palsy. J Hand Surg [Am] 2006;31:474-82.

8. Yang Z, Huang $\mathbf{F}$, Zhang $\mathbf{S}$. Restoration of supination of forearm by flexor carpi radialis transfer. Zhongguo Xiu Fu Chong Jian Wai Ke Za Zhi 1998;12:336-8 (in Chinese).

9. Price AE, Grossman JA. A management approach for secondary shoulder and forearm deformities following obstetrical brachial plexus injury. Hand Clinics 1995;11:607-17.

10. Zancolli EA, Zancolli ER. Palliative surgical procedures in sequelae of obstretrical palsy. Hand Clin 1988;4:643-69. 